\title{
Estimación de biomasa aérea y carbono con Teledetección en bosques alto-Andinos de Boyacá, Colombia. Estudio de caso: Santuario de Fauna y Flora Iguaque
}

\author{
Aboveground biomass and carbon estimation in the high- \\ Andean forests of Boyacá, Colombia using remote sensing. \\ Case study: Santuario de Fauna y Flora Iguaque
}

\author{
Mauricio Alejandro Perea-Ardila \\ Hernán ]. Andrade-Castañeda ${ }^{2}$ \\ Milena A. Segura-Madrigal ${ }^{3}$
}

Recibido 2 de septiembre de 2020; aceptado 30 de noviembre de 2020

\section{RESUMEN}

La Teledetección es clave para el monitoreo de bosques naturales. En este estudio, se estimó la biomasa aérea (AGB) y el carbono (C) con teledetección en bosques del Santuario de Fauna y Flora Iguaque (SFFI) en Boyacá, Colombia. Se establecieron 23 parcelas temporales de muestreo (PTM) de $250 \mathrm{~m}^{2}$ cada una y se midieron los árboles con diámetro a la altura del pecho (dap) $\geq 10 \mathrm{~cm}$. La AGB real se estimó con una ecuación alométrica para especies alto-andinas y se multiplicó por 0,5 para estimar el C. Solo nueve PTM cumplieron con criterios de una densidad mínima de 30 árboles por parcela, estas se correlacionaron con tres índices de vegetación: el Índice de Vegetación de Diferencia Normalizada, el Índice de Vegetación Ajustado al Suelo y el Índice de Vegetación Mejorado (NDVI, SAVI y EVI) derivados de dos imágenes Landsat 8 OLI en época seca y lluviosa del 2016. Se desarrolló un modelo para estimar AGB con base en 
índices de vegetación para construir mapas de carbono. El mejor modelo estuvo basado en el NDVI de la época seca ( $R^{2}$ ajustado $=0,79$ y error medio cuadrático $=17,1 \mathrm{Mg} / \mathrm{ha}$ ). Los bosques del SFFI almacenaron en promedio $36,6 \mathrm{Mg} \mathrm{C} /$ ha en AGB. Asimismo, acumularon $163 \mathrm{Gg} \mathrm{CO}_{2} \mathrm{e}$ traducidos en emisiones evitadas a la atmósfera por deforestación. Este estudio de caso presenta un primer ejercicio en la estimación de AGB y C con herramientas de Teledetección para el monitoreo de bosques en áreas protegidas de importancia regional y servirá como referente para futuras investigaciones que involucren el monitoreo satelital de bosques naturales de la región.

Palabras clave: ecosistemas forestales, monitoreo, imágenes de satélite, indices de vegetación, Landsat 8.

\section{Abstract}

Remote sensing is very important for monitoring the natural forests. In this study was estimated the aboveground biomass (AGB) and carbon (C) with remote sensing in the Santuario de Fauna y Flora Iguaque (SFFI) in Boyacá, Colombia. A total of 23 temporal sampling plots (TSP) of $250 \mathrm{~m}^{2}$ each were installed and all trees with diameter at breast height $(\mathrm{dbh}) \geq 10 \mathrm{~cm}$ were measured. The real AGB was estimated using an allometric equations for species from high-Andean forests and was multiplied for 0,5 to estimate C. Only nine TSP fulfilled the criterion of a minimal tree density of 30 trees per plot, these were correlated with three vegetation indexes, Normalized Difference Vegetation Index, Soil Adjusted Vegetation Index and Enhanced Vegetation Index (NDVI, SAVI and EVI) derived from two Landsat 8 images from dry and rainy season in 2016. A model to estimate AGB based on a vegetation index was developed in order to build carbon maps. The best model was based on NDVI in the dry season (adjusted $\mathrm{R}^{2}=0.79$ and root of mean square error of $17.1 \mathrm{Mg} / \mathrm{ha}$ ). The forests in the SFFI stored a mean of $36.6 \mathrm{Mg} \mathrm{C/ha}$ in AGB. Also, was accumulated $163 \mathrm{Gg} \mathrm{CO}_{2} \mathrm{e}$ in the forests the SFFI that correspond emissions evited at the atmosphere. This case study was presented as the first exercise for estimated AGB and C with remote sensing tools for forest monitoring in protected areas of environmental importance and will serve as a reference for future investigations for the satellite monitoring of the region's natural forests.

Key words: Forest ecosystem, monitoring, satellite images, vegetation in-dexes, Landsat 8.

\section{Introducción}

Los bosques naturales son de gran importancia para comprender las dinámicas ecológicas del planeta (Brown, 1997), considerando que la biomasa forestal es un importante reservorio de carbono (C) juega un papel fundamental en la 
regulación de su ciclo global y en la mitigación del cambio climático (Main-Knorn et al., 2013; Timothy et al., 2016; Andrade-Castañeda et al., 2017).

La mayor cantidad de $C$ que se almacena en los árboles se fija a través del proceso de la fotosíntesis y se acumula en la biomasa aérea (AGB por sus siglas en inglés) (Roy \& Ravan, 1996; Rodríguez-Veiga et al., 2017). El monitoreo de los reservorios de $\mathrm{C}$ es importante para la comprensión del ciclo de este elemento y para reducir las emisiones de $\mathrm{CO}_{2}$ presentes en la atmósfera (Timothy et al., 2016). La AGB proporciona estimaciones del C en la vegetación forestal, ya que aproximadamente el 50\% de la biomasa es C (Brown, 1997) y es posible realizar estimaciones de la cantidad de $\mathrm{CO}_{2}$ que se libera a la atmósfera por algún disturbio (IPCC, 2007).

Los métodos para la estimación directa de AGB en campo presentan buenos resultados, sin embargo, son de un costo muy elevado y requieren de un gran despliegue logístico, este método contempla la cosecha de árboles para el desarrollo de modelos alométricos locales, lo que se traduce en la destrucción del bosque (Zhu \& Liu, 2015).

Los sensores remotos son una fuente de datos para la estimación indirecta de la AGB y el C (Martínez-Barrón et al., 2016; Pechanec et al., 2017). Este método indirecto presenta una ventaja con respecto a los métodos tradicionales debido a la practicidad para el procesamiento rápido de grandes volúmenes de datos y por la correlación entre bandas espectrales y los datos de inventarios forestales (Lu et al., 2012). Esta característica lo convierten en un método alternativo para la estimación de AGB y C en grandes áreas forestales (Lu, 2006). Las imágenes Landsat son datos de observación de la Tierra que se han utilizado para el monitoreo y la estimación de AGB y C de bosques naturales (Powell et al., 2010; Qiu et al., 2019), son de libre acceso a la comunidad científica y representan una alternativa de bajo costo para llevar a cabo el monitoreo de bosques utilizando imágenes de satélite (Banskota et al., 2014; Zhu et al., 2019).

Los índices de vegetación (IV) calculados a partir de imágenes de sensores remotos son comúnmente utilizados en las estimaciones de AGB y C (Imran \& Ahmed, 2018). Los IV se obtienen de la división de las bandas espectrales (reflectividad) de sensores remotos (Chuvieco, 2010) lo que permite extraer información relacionada con la vegetación (Gilabert et al., 1997).

Diferentes estudios han utilizado los IV para la estimación de AGB y C; tal es el caso de Saatchi et al. (2007), quienes estimaron la AGB de la cuenca amazónica con el uso de imágenes de sensores remotos del sensor ModerateResolution Imaging Spectroradiometer (MODIS) y datos de inventarios forestales de los siete países que la conforman. Por su parte, Li et al., (2019) emplearon imágenes Landsat 8 de diferentes estaciones del año, datos de inventarios forestales y doce IV para estimar la AGB de los bosques de la provincia de Hunan en China; asimismo, Gizachew et al. (2016) utilizaron imágenes del Landsat 8, datos de campo y siete IV para estimar la AGB y el C de ecosistemas forestales en el distrito de Liwale, sureste de Tanzania. Otro ejemplo de aplicación es el 
reportado por Padrón \& Navarro-Cerrillo (2007), quienes basaron su estudio en el uso de imágenes Landsat 7, datos de parcelas forestales y seis IV para estimar la AGB de bosques de especies forestales (Prosopis pallida) en la provincia de Piura (noreste de Perú, América).

A nivel local, el Instituto de Hidrología, Meteorología y Estudios Ambientales de Colombia (IDEAM) ha realizado estudios sobre la estimación de la AGB y C de los ecosistemas forestales de país utilizando imágenes de sensores remotos, 3020 parcelas de inventarios forestales de diferentes tamaños, temporalidad y de tres IV (Galindo et al., 2011).

De igual manera, Anaya et al. (2009) propusieron un método para estimar AGB en la zona continental de Colombia utilizando imágenes MODIS y datos de 44 parcelas reportadas en la literatura para bosques primarios y otros tipo de coberturas; otro enfoque para la estimación de C es el propuesto por Clerici et al. (2016), quienes utilizaron datos de sensores remotos de alta resolución espacial, datos de AGB derivados de parcelas en bosques secundarios periurbanos y cinco IV en el altiplano cundiboyacense en los Andes Orientales de Colombia. Estos estudios denotan la importancia que presentan los sensores remotos frente al monitoreo de la AGB y el C en ecosistemas forestales.

El Santuario de Fauna y Flora Iguaque (SFFI) es un área protegida del orden nacional y de gran importancia ecológica, alberga gran cantidad de especies vegetales de ecosistemas Andinos y alto-Andinos que son base para la biodiversidad y la regulación hídrica de la región (Fernández-Méndez et al., 2016). Pese a su importancia ecológica, los bosques Andinos del SFFI están en constante presión debido a la ampliación de la frontera agropecuaria (deforestación, pastoreo y quemas), siendo prácticas que pueden aumentar las emisiones de Gases de Efecto Invernadero (GEI) a la atmósfera y así contribuir al cambio climático (Villareal et al., 2017).

Según el reciente informe del Atlas de Carbono para el Sistemas de Áreas Protegidas de los Andes Nororientales de Colombia, el SFFI presentó una cifra de deforestación neta de 281,9 ha entre 1990 y 2012, pudiéndose liberar aproximadamente 71 458,3 t $\mathrm{CO}_{2}$ e a la atmósfera (Parques Nacionales Naturales, 2018) por lo que la necesidad del monitoreo de la AGB y C en bosques naturales es fundamental.

Los objetivos de este estudio fueron: 1) realizar un inventario forestal exploratorio en los bosques del SFFI; 2) estimar la AGB y el C real con datos de campo y ecuaciones alométricas; 3) la posterior correlación de la AGB y tres IV mediante técnicas estadísticas y de teledetección; y 4) generar cartografía a resolución de $30 \mathrm{~m}$ de la $\mathrm{AGB}$ y el $\mathrm{C}$ del SFFI y calcular las emisiones de $\mathrm{CO}_{2} \mathrm{e}$ evitadas por deforestación. 


\section{2. Área de estudio}

El SSFI se encuentra localizado sobre la Cordillera Central de los Andes en el nororiente colombiano (Figura 1). Esta área protegida posee una superficie de 6923 ha, presenta elevaciones entre los 2400 y 3890 m y alberga bosques Andinos y alto-Andinos con dominancia de especies forestales de los géneros Weinmannia spp, Clusia spp y Miconia spp. El SFFI se caracteriza por presentar una distribución bimodal de lluvias, los meses secos se encuentran entre diciembre-febrero y entre junio-agosto y meses de mayor precipitación están comprendidos entre marzo-mayo y entre septiembre-noviembre (Parques Nacionales Naturales, 2006; Villareal et al., 2017).
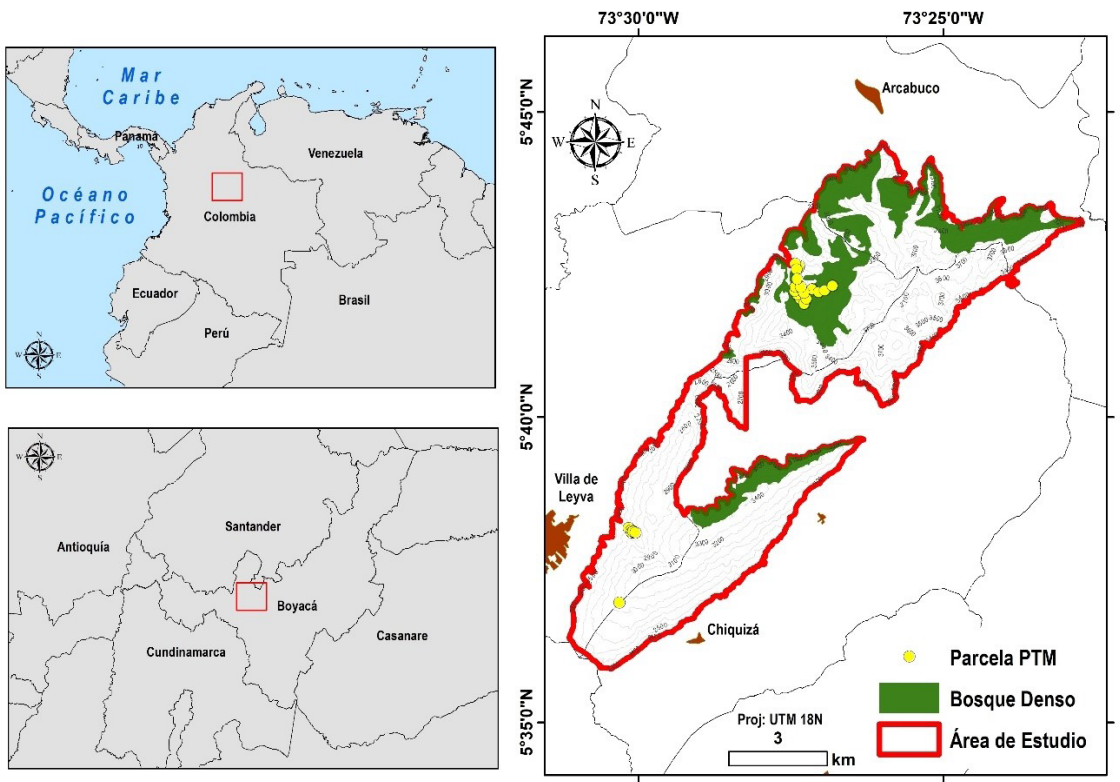

Figura 1. Localización del Santuario de Fauna y Flora Iguaque, Colombia.

\section{Metodología}

El flujo de trabajo de este estudio se detalla en la Figura 2, se incluyen mediciones en campo, análisis y procesamiento de imágenes de satélite, cálculo de IV, desarrollo de modelos de biomasa con base en IV y desarrollo de mapas de AGB y $C$ en el SFFI. Los análisis estadísticos fueron realizados con el software InfoStat versión 2016 (Di Rienzo et al., 2016), el manejo de datos geográficos y análisis de las imágenes Landsat 8 fueron realizados con el software ArcGIS 10.3 (ESRI, 2014). 


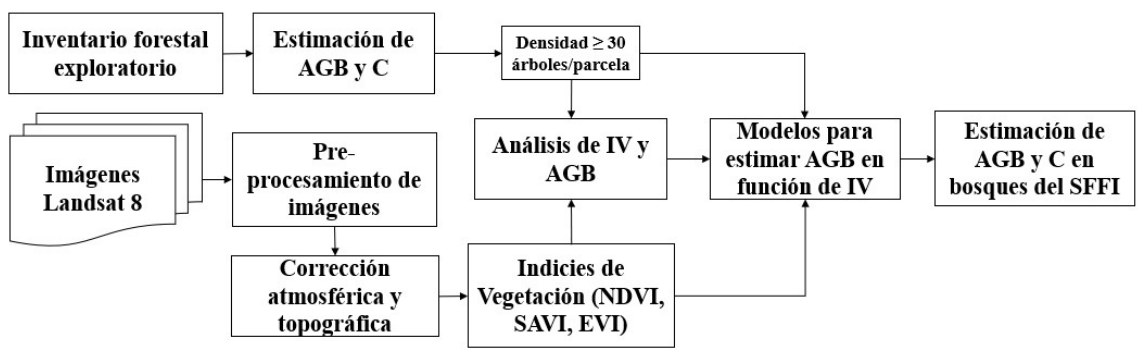

Figura 2. Flujograma para la estimación de la biomasa aérea (AGB) y C en el Santuario de Fauna y Flora Iguaque en Boyacá, Colombia. IV: índice de vegetación.

\subsection{Inventario forestal exploratorio}

La localización de los "bosques densos" se realizó mediante la descarga de la capa (shapefile) oficial de coberturas y usos de la tierra para el año 2012 del SFFI alojada en el geovisor de Parques Nacionales Naturales de Colombia (https:// mapas.parquesnacionales.gov.co/). En campo y con ayuda de cartografía se establecieron 23 Parcelas Temporales de Muestro (PTM) al azar, las PTM fueron de $250 \mathrm{~m}^{2}(10 \times 25 \mathrm{~m})$ se consideró las recomendaciones de Corral-Rivas et al. (2013), para el inventario forestal.

Asimismo, se registró el diámetro a la altura del pecho (dap) $\geq 10 \mathrm{~cm}$ para cada árbol en cada parcela con una cinta diamétrica. Las PTM fueron ubicadas geográficamente en campo con un GPS GARMIN eTrex Vista Hcx, registrando el punto central de la PTM con remediciones para obtener una precisión de $\pm 3 \mathrm{~m}$. El trabajo de campo se realizó en el mes de septiembre del año 2016.

\subsection{Estimación de biomasa arriba del suelo y carbono}

Se estimó la AGB total para cada árbol individual de la PTM por medio de la ecuación alométrica (Ecuación 1) propuesta por (Lerma \& Orjuela, 2014)1. Esta ecuación se desarrolló a partir del método directo (destructivo) para especies de bosques alto-Andinos de Anaime en Cajamarca (Colombia), el modelo se desarrolló para especies forestales de Weimannia aurículata, Miconia spp y Baccharis spp y de similares condiciones ambientales a las del SFFI.

$$
\operatorname{Ln}(B t)=-1,85+2,11^{*} \operatorname{Ln}(\text { dap })
$$

Donde:

Bt: Biomasa aérea ( $\mathrm{kg} / \mathrm{árbol})$

Ln: Logaritmo natural 
dap: Diámetro a la altura del pecho $(\mathrm{cm})$

$\mathrm{R}^{2} \mathrm{aj}$ : Coeficiente de determinación ajustado

La AGB estimada para las PTM fue extrapolada a Mg/ha y el C se multiplicó por 0,5 ya que es el valor recomendado por el Grupo Intergubernamental de Expertos sobre el Cambio Climático (IPCC, por sus siglas en inglés) (IPCC, 2007).

\subsection{Imágenes Landsat 8}

Se emplearon dos imágenes del Satélite Landsat 8 OLI-Level 1 del año 2016: una del 2 de febrero en época seca (USGS, 2016a) y una del 23 de mayo en época Iluviosa (USGS, 2016b) (Tabla 1). Estas imágenes fueron proporcionadas por la Servicio Geológico de los Estados Unidos (USGS, por sus siglas en inglés) a través del portal Land Viewer del EOS Data Analytics (https://eos.com/landviewer).

Tabla 1. Características de las imágenes del satélite Landsat 8 OLI-Level 1

\begin{tabular}{lcc}
\hline \multicolumn{1}{c}{ Propiedad } & Imagen febrero 2016 & Imagen mayo 2016 \\
\hline ID de la imagen & LC80070562016032LGN00 & LC80070562016144LGN00 \\
\hline Path/row & $007 / 056$ & $007 / 056$ \\
\hline Fecha de captura & 1 de febrero de 2016 & 23 de mayo de 2016 \\
\hline Acimut solar & 128,76189712 & 56,31905694 \\
\hline Elevación solar & 52,96286801 & 61,21069074 \\
\hline Cubrimiento de nubes & $4,70 \%$ & $55,94 \%$ \\
\hline Zona UTM & UTM 18 N & \\
\hline Resolución espacial & 30 m Bandas multiespectrales \\
\end{tabular}

De igual manera, se descargó un modelo digital de elevaciones (MDE) con resolución de 1 arco/segundo (30 m resolución espacial) de la misión Advanced Spaceborne Thermal Emission and Reflection Radiometer (ASTER), proyecto Global Digital Elevation Map Announcement (GDEM) versión 2 (NASA-METI, 2011) el cual fue accedido través del portal oficial del Japan Space Systems (http://www.jspacesystems.or.jp/ersdac/GDEM/E/). 


\subsection{Preprocesamiento de las imágenes}

\subsubsection{Corrección atmosférica}

Se realizó la conversión de los niveles digitales (ND) a reflectancia al Tope de la Atmosfera (ToA, por sus siglas en inglés) (Ecuación 2 y Ecuación 3), empleando los parámetros establecidos por Ariza (2013) y el USGS (2018). Esto se realizó debido a que la reflectancia de la superficie de la Tierra capturada por los sensores ópticos se ve directamente influenciada por los efectos atmosféricos como el vapor de agua y los aerosoles, por lo cual se hace necesario el mejoramiento radiométrico de las imágenes para mejorar su calidad (AguilarArias et al., 2014; Nguyen et al., 2015).

$$
\begin{gathered}
\rho \lambda^{\prime}=M \rho^{*} \mathrm{Q} c a l+A \rho \\
\rho \lambda=\frac{\rho \lambda^{\prime}}{\operatorname{Sin}(\theta)}
\end{gathered}
$$

Dónde:

$\mathrm{p} \lambda$ `: Valor de reflectancia planetaria ToA, sin corrección por ángulo solar;

Mp: Factor multiplicativo de escalado de la banda (metadato);

Ap: Factor aditivo de escalado de la banda (metadato);

Qcal: Valor del pixel (DN);

$\theta$ : $\quad$ Ángulo de elevación solar (radianes).

\subsubsection{Corrección topográfica}

Se utilizó el método de corrección topográfico C-correction (Ecuación 4 y Ecuación 5) propuesto por Teillet et al. (1982), corrección muy aplicada para imágenes Landsat (Wu et al., 2004; Hantson \& Chuvieco, 2011). El método se basa únicamente en la correlación observada entre la reflectancia y el coseno de la iluminación incidente (Banskota et al., 2014). La constante C se estimó empleando el MDE para crear un modelo de relieve sombreado (Hillshade) el cual se correlacionó a través de una regresión lineal con los valores de reflectancia ToA de ambas imágenes $(C=b / m)$. Esta corrección se realizó porque los bosques naturales del SFFI se encuentran sobre laderas y terrenos irregulares, lo cual puede afectar la reflectividad capturada por el sensor y pueden presentar variaciones en la respuesta espectral de los bosques (Hantson \& Chuvieco, 2011; Pimple et al., 2017).

$$
\begin{gathered}
L_{H}=L_{T}\left\{\frac{\operatorname{Cos}(\varnothing)+C}{\operatorname{Cos}(i)+C}\right\} \\
L_{-} T=m \operatorname{Cos}(i)+b
\end{gathered}
$$


Donde:

$\mathrm{L}_{\mathrm{n}}$ : Iluminación topográfica corregida;

L: Iluminación topográfica no corregida;

i: Ángulo de incidencia (grados);

$\varnothing$ : Ángulo solar Zenith (grados),

C: Constante de corrección,

b y n: Intercepto y pendiente de la regresión lineal.

\subsection{3. Índices de vegetación}

Con base en las imágenes corregidas, se estimaron tres IV (Tabla 2), los cuales son operaciones cuantitativas generadas a partir de los valores corregidos de los pixeles de las bandas espectrales y generando valores únicos para determinar características de la vegetación (Chuvieco, 2010). Los IV seleccionados en este estudio fueron implementados en Colombia para la estimación y monitoreo de AGB en bosques naturales empleando sensores remotos (Galindo et al., 2011).

Tabla 2. Índices de vegetación empleados

\begin{tabular}{|c|c|c|}
\hline Índice & Ecuación & Fuente \\
\hline NDVI & $\frac{N I R-R o j o}{N I R+R o j o}$ & Rouse et al., 1974 \\
\hline SAVI & $\frac{N I R-R o j o}{N I R+R o j o+L}(1+L)$ & Huete, 1988 \\
\hline EVI & G. $\frac{\text { NIR-Rojo }}{L_{2}+N I R+C_{1} \cdot R e d-C_{2} \cdot A z u I}$ & Huete et al., 1999 \\
\hline
\end{tabular}

El Índice de Diferencia Normalizada (NDVI) se expresa como la diferencia entre las bandas infrarrojas cercanas y rojas normalizadas, es muy sensible a identificar vegetación y presenta valores entre - 1 y 1 donde los valores positivos constituyen vegetación (Silleos et al., 2006; Rhyma et al., 2020). Asimismo, el Índice de Vegetación Ajustado al Suelo (SAVI) disminuye los efectos provocados por el suelo principalmente, trabaja igual que el NDVI incluyendo un factor de ajuste $L$, el cual puede tomar valores de entre 0 y 1 según la densidad de la vegetación (Eastman, 2006). En este estudio, se utilizó un factor de $L$ de 0,5 asumiendo una densidad media en la estructura de los bosques del SFFI.

Finalmente, el Índice de Vegetación Mejorado (EVI) es una mejora del NDVI, además, del factor $L$, incluye los parámetros $C_{1}, C_{2}$ y la banda azul que buscan corregir alguna afectación por las condiciones atmosféricas y la influencia del 
suelo en la vegetación (Huete et al., 1999). Una de las características principales de estos IV es que se basan en la pendiente y son comúnmente utilizados para el estudio de la vegetación, su estado y abundancia (Silleos et al., 2006). De igual manera, se generó una máscara de nubes con la banda BQA para la imagen de época lluviosa con el fin de trabajar con píxeles de superficie.

\subsubsection{Modelos para estimar AGB en función de los índices de vegetación}

La variación en la abundancia de árboles y la estructura de la vegetación incide en la densidad de las copas en una parcela, esto influencia la estimación de la AGB con datos de sensores remotos (Li et al., 2019). Por tal razón, se seleccionaron las PTM que tuviesen una densidad $\geq 30$ árboles/parcela con dap $\geq$ a $10 \mathrm{~cm}$, adicionalmente, se extrajo una máscara con el valor mínimo y máximo del NDVI de las PTM para definir el rango de IV en el que se encontraron ese tipo de bosques.

El valor de los IV y AGB se extrajo a través de la herramienta "Extract Values" de ArcGIS. Finalmente, nueve parcelas cumplieron con la condición, para una representatividad de 0,23 ha. En el caso de que la parcela quedara en medio de dos o más píxeles (Figura 3), se tomó el valor de promedio de los píxeles vecinos.
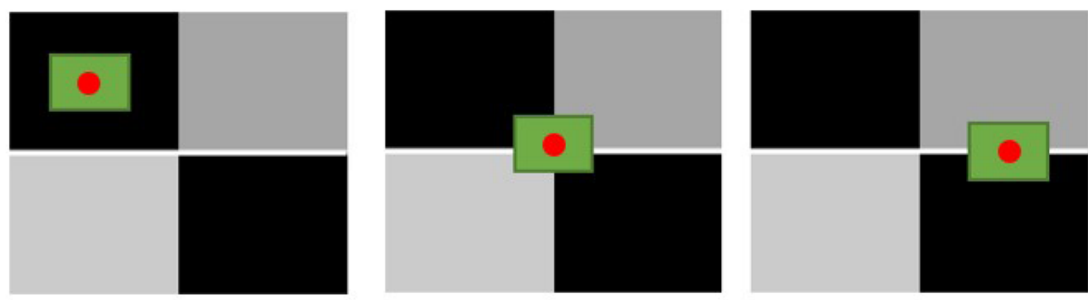

Figura 3. Posible ubicación de las parcelas temporales de muestreo (verde) y punto GPS (rojo) en el píxel de la imagen Landsat 8.

Se realizó el análisis de correlación de Pearson entre los valores cuantitativos de la AGB y los IV y se probó modelos de regresión lineal con las variables transformadas logarítmicamente y sin transformar para definir los modelos de mejor ajuste. En este caso, la AGB fue la variable dependiente y los IV la variable independiente. Los modelos se evaluaron con base en el coeficiente de determinación $\left(R^{2}\right)$, coeficiente de determinación ajustado ( $R^{2}$ adj), el error cuadrático medio de predicción (ECMP), el Criterio de Información Akaike (AIC) y el Criterio de Información Bayesiano (BIC) recomendados por Segura \& Kanninen (2005); Segura \& Andrade (2008) y Andrade et al. (2014). Adicionalmente, se estimó el Error Medio Cuadrático (EMC) con los valores observados (parcelas) y estimados (modelo) de AGB según lo recomendado por Günlü et al. (2014). 


\subsection{Distribución de la AGB y Cen bosques del SFFI}

Se aplicó la fórmula del modelo generado con el fin de conocer la distribución de AGB y C en el SFFI, empleando la "calculadora raster", y se procedió a realizar una salida gráfica donde se plasmaron los resultados obtenidos. Asimismo, para una mejor visualización de los resultados, se propuso clasificar los valores en tres rangos que comprenden $>50 \mathrm{y} \leq 100,>100 \mathrm{y} \leq 140 \mathrm{y}$ de $>140 \leq 170 \mathrm{Mg} /$ ha para AGB y entre $>28$ y $\leq 50,>50$ y $\leq 70$ y $>70 \leq 85 \mathrm{Mg}$ C/ha y se calculó el área para cada rango de distribución. Se multiplicó el contenido de AGB y $C$ promedio con el área estimada de los bosques naturales donde se estimó el almacenamiento total. Finalmente, se estimó el equivalente de dióxido de carbono $\left(\mathrm{CO}_{2} \mathrm{e}\right)$ aplicando el factor de 3,67 recomendado por el IPCC, (2007), con el fin de conocer las emisiones evitadas por deforestación para la estimación total del C.

\section{Resultados}

\subsection{Estimación de biomasa y carbono en campo}

Los bosques del SFFI presentaron una abundancia de 602 árboles/ha y dap promedio de $15,8 \mathrm{~cm}$. La especie forestal de mayor abundancia fue Weinnmania spp conocida en la zona comúnmente como "Encenillo". Asimismo, se obtuvo un promedio de AGB del orden de los 73,1 Mg/ha (168,0 $\pm 11,2 \mathrm{Mg} / \mathrm{ha}$ ) lo que representó $36,6 \mathrm{Mg}$ C/ha (84,0 $\pm 5,61 \mathrm{Mg}$ C/ha) (Figura 4). Las PTM con mayor biomasa fueron 11 y 6 con 168,0 y 160,0 Mg/ha, respectivamente.

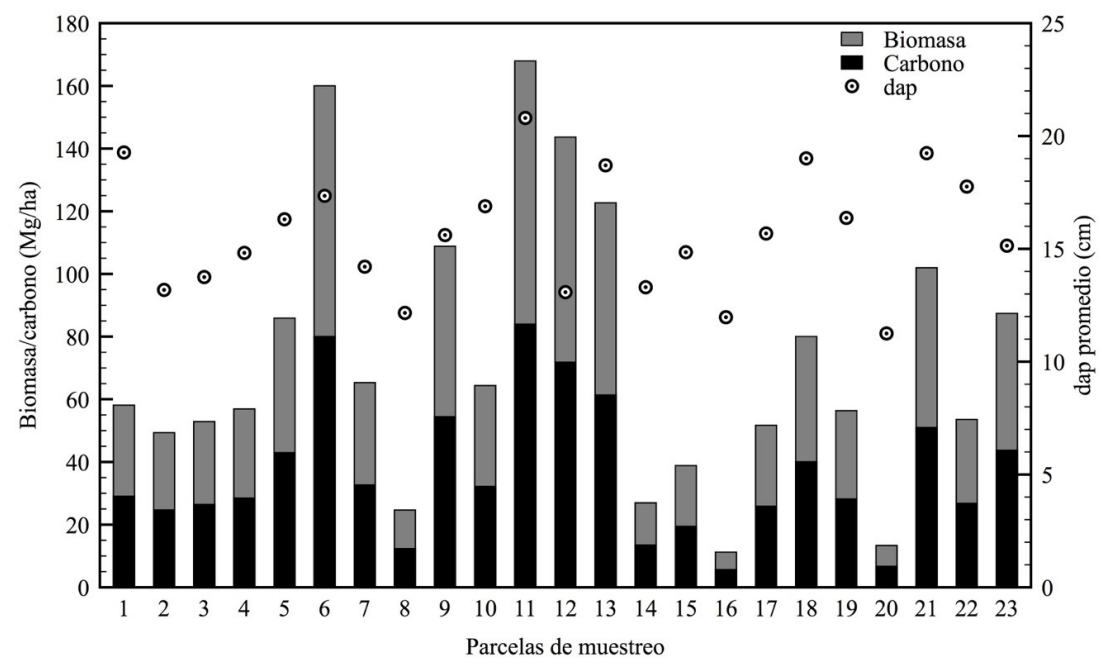

Figura 4. Estimación de los contenidos de AGB y $C$ en las Parcelas Temporales de Muestreo del Santuario de Fauna y Flora Iguaque. 


\subsection{Mejoramiento de las imágenes Landsat 8}

Los ND (números digitales) de las imágenes se transformaron a valores de reflectancia ToA (valores que oscilan entre 0 y 1 ), observando una mejora radiométrica para ambas épocas eliminando en gran medida los efectos atmosféricos y topográficos presentes originalmente (Figura. 5). La imagen de mayo presentó algunas nubes sobre la parte este y noreste del área de estudio; sin embargo, visualmente se observa una mejora en el contraste y se pueden detallar características propias de las coberturas presentes como bosques densos (rojo oscuro), Páramo (marrón) vegetación menos densa (rojo claro) y floraciones rocosas (tono gris claro) en la superficie terrestre del SFFI.
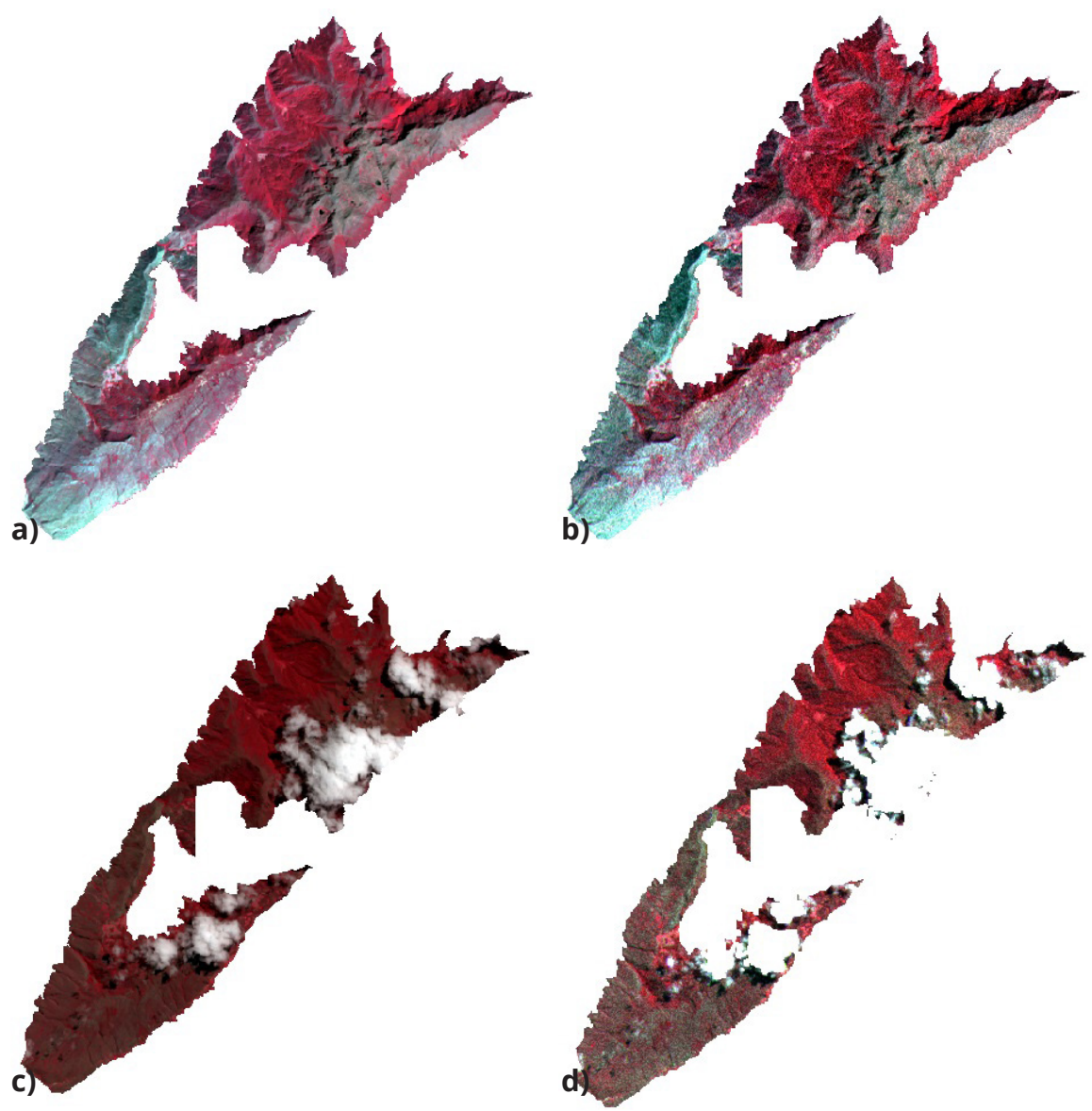

Figura 5. Mejoramiento de imágenes Landsat 8 para el SFFI (RGB 543); a) imagen de febrero sin corrección; b) imagen de febrero con corrección; c) imagen de mayo sin corrección y d) imagen de mayo con corrección. 


\section{3. Índices de vegetación}

Los IV presentaron diferencias en valores para ambas épocas (Figura 6). El EVI de mayo obtuvo el valor máximo de 1,0; a su vez, el NDVI de febrero presentó el valor más bajo con -0,48. En este caso, los tonos verdes más intensos se encontraron en la parte Norte, parches continuos sobre la zona Este y Sur del SFFl; mientras que los tonos de rojo por su parte representan otro tipo de coberturas. Los IV para el mes de febrero presentaron para el NDVI, SAVI y EVI un valor promedio de 0,$51 ; 0,26$ y 0,33 y para el mes de mayo de 0,$49 ; 0,26$ y 0,37 respectivamente.

\section{Índices de Vegetación de febrero de 2016}
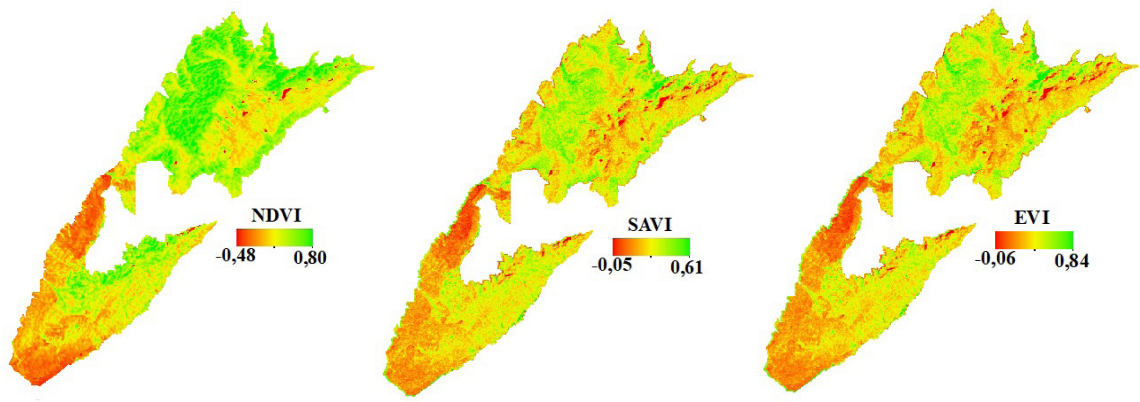

Índices de Vegetación de mayo de 2016
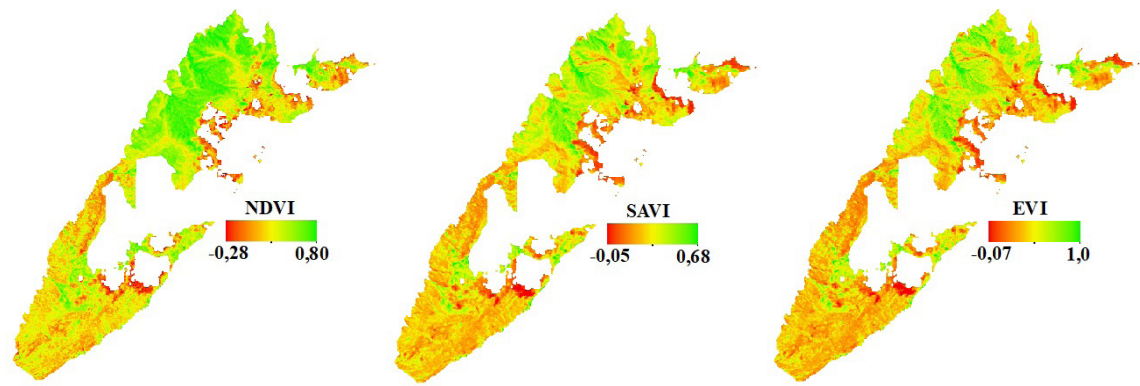

Figura 6. Índice de vegetación determinados para la época seca (febrero) y lluviosa (mayo) para el SFFI.

\subsubsection{Análisis de valores de índices de vegetación}

El AGB para las nueve PTM que cumplieron con el criterio de densidad arbórea obtuvieron un promedio estimado de 106,3 Mg/ha (Figura 7) y valores promedio 
de NDVI, SAVI y EVI para febrero de 0,64; 0,32 y 0,42, respectivamente y valores
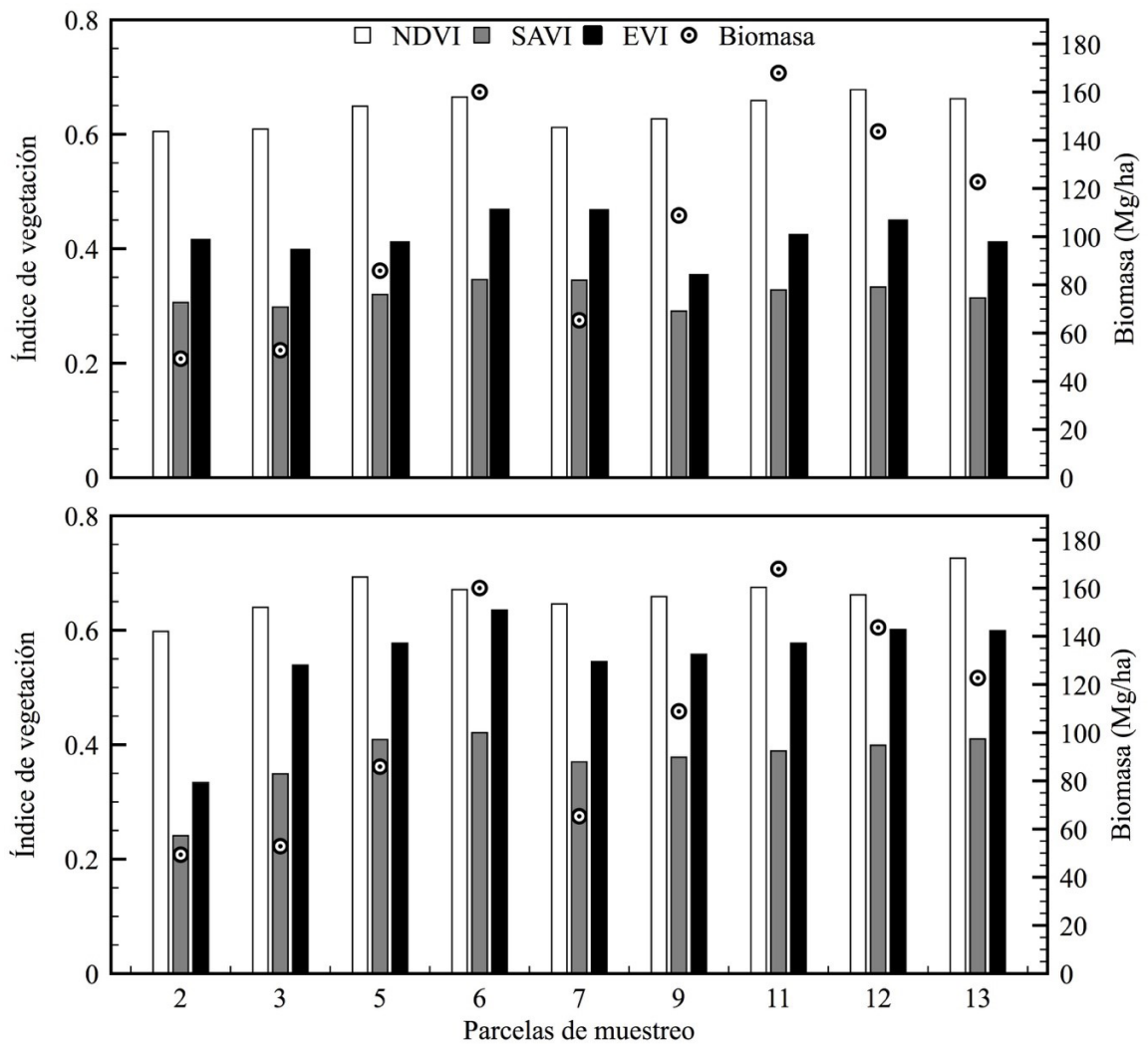

Figura 7. Comparación de valores de índice de vegetación vs biomasa aérea para el SFFI.

ligeramente superiores para mayo de 0,$66 ; 0,37$ y 0,55 , respectivamente. La PTM 12 presentó un valor de NDVI de 0,68, siendo el mayor valor registrado para febrero.

\subsubsection{Modelos de AGB basados en índices de vegetación}

Los rangos del NDVI mínimos y máximos que se utilizaron para definir los bosques según el criterio de densidad de copas estuvieron entre 0,68 $\pm 0,61$ respectivamente. El resultado del análisis de correlación de Pearson demostró que el IV de mayor correlación correspondió al NDVI de febrero con un valor de $\mathrm{R}=0,88$ (Tabla 4). Asimismo, para la imagen de mayo presentó fuertes correlaciones con el SAVI y EVI ambos con R= 0,7. El EVI de febrero fue el de menor correlación con un valor de $\mathrm{R}=0,3$. 
Tabla 4. Coeficientes de correlación de Pearson entre la biomasa aérea y los índices de vegetación

\begin{tabular}{|c|c|c|c|c|c|c|c|c|}
\hline \multirow{2}{*}{ Época } & \multirow{2}{*}{ Parámetro } & \multirow{2}{*}{$A G B_{t}$} & \multicolumn{3}{|c|}{ Seca } & \multicolumn{3}{|c|}{ Lluviosa } \\
\hline & & & $N D V I$ & SAVI & $E V I$ & $N D V I$ & SAVI & EVI \\
\hline & AGBt & 1 & - & - & - & - & - & - \\
\hline \multirow{3}{*}{$\begin{array}{l}\text { Seca } \\
\text { (febrero) }\end{array}$} & NDVI & 0,88 & 1 & - & - & - & - & - \\
\hline & SAVI & 0,4 & 0,46 & 1 & - & - & - & - \\
\hline & EVI & 0,3 & 0,31 & 0,95 & 1 & - & - & - \\
\hline \multirow{3}{*}{$\begin{array}{l}\text { Lluviosa } \\
\text { (mayo) }\end{array}$} & NDVI & 0,6 & 0,71 & 0,18 & 0 & 1 & - & - \\
\hline & SAVI & 0,7 & 0,74 & 0,42 & 0,2 & 0,84 & 1 & - \\
\hline & $\mathrm{EVI}$ & 0,7 & 0,72 & 0,42 & 0,22 & 0,77 & 0,98 & 1 \\
\hline
\end{tabular}

Donde: AGBt: Biomasa aérea total.

Dentro del proceso de prueba para los diferentes modelos y según los parámetros de ajuste y evaluación se observó que el modelo tipo exponencial (Figura 8) arrojó los mejores resultados presentando un $R^{2}$ de 0,82 ( $R^{2}$ adj = 0,79) para el NDVI de época seca. Los contenidos de AGB estimados y observados alcanzaron un EMC de 17, $11 \mathrm{Mg} /$ ha con el modelo de mejor ajuste.
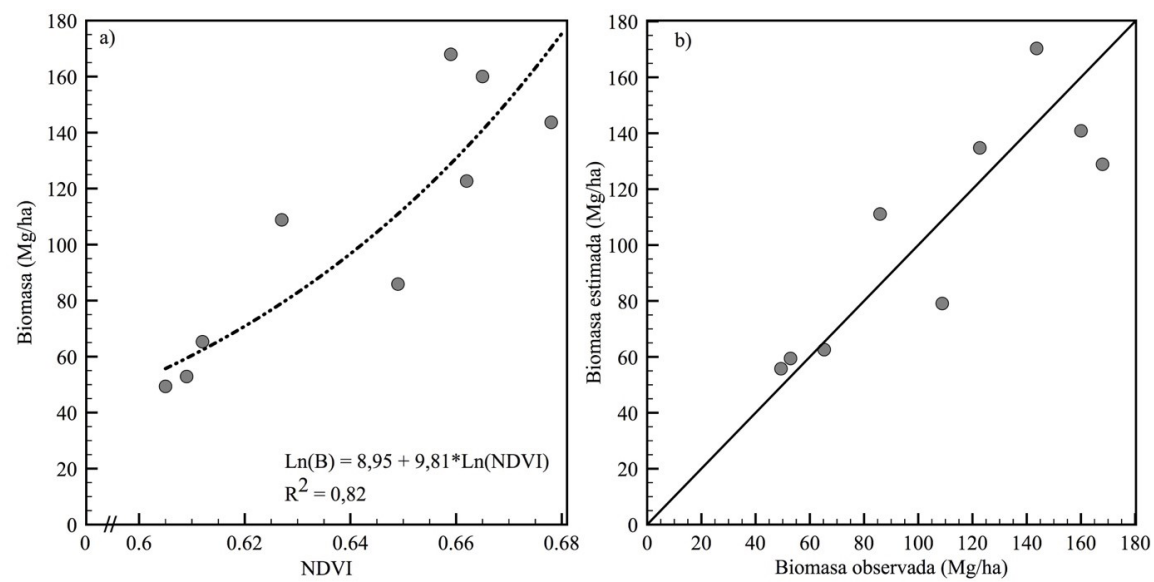
Figura 8. (a) Modelo para estimar de estimación de AGB en función del NDVI en época seca (b) Relación entre la AGB estimada y observada del SFFI.

\subsubsection{Distribución de la AGB y C en bosques del SFFI}

En total se determinó un área de 1 213,62 ha de bosques naturales lo que correspondió al 17,5\% del total del área del SFFI (Tabla. 5). Asimismo, la clase de AGB con de mayor ocupación correspondió a la clase 1 con el 8,23\%.

Tabla 5. Distribución de rangos de biomasa aérea y Carbono

\begin{tabular}{ccccc}
\hline Clase & $\begin{array}{c}A G B \\
(M g / h a)\end{array}$ & $\begin{array}{c}C \\
(M g C / h a)\end{array}$ & $\begin{array}{c}\text { Área } \\
(\text { ha })\end{array}$ & $\begin{array}{c}\text { Área } \\
(\%)\end{array}$ \\
\hline 1 & $>50 \leq 100$ & $>28 \leq 50$ & 569,80 & 8,23 \\
\hline 2 & $>100 \leq 140$ & $>50 \leq 70$ & 421,36 & 6,09 \\
\hline 3 & $>140 \leq 170$ & $>70 \leq 85$ & 222,46 & 3,21 \\
\hline \multicolumn{5}{c}{ Superficie del SFFI } \\
\hline
\end{tabular}

Los mayores contenidos de AGB y C para la Clase 1 se encuentran en alturas que corresponden a los 3000 y $3300 \mathrm{~m}$; en la franja de bosques al sureste que presenta valores dominantes. A su vez, la mayor AGB se concentra en pequeños fragmentos de la zona norte del SFFI distribuidos heterogéneamente (Figura 9).
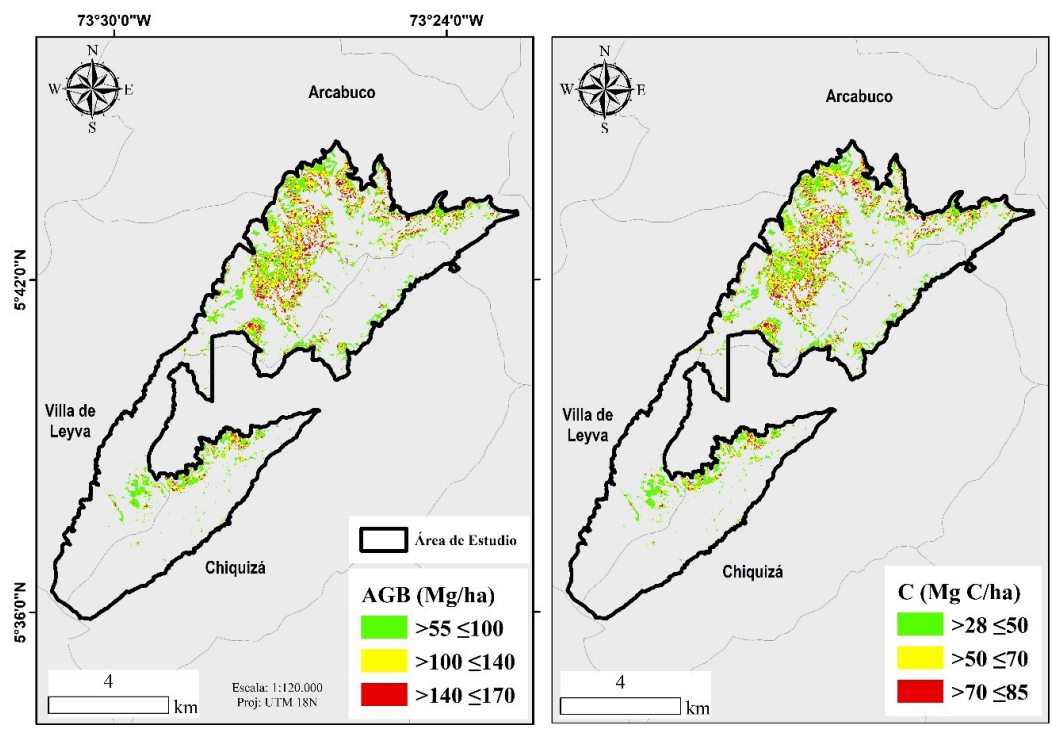
Figura 9. Estimación de AGB y C en los bosques del Santuario de Fauna y Flora Iguaque.

Los bosques naturales del SFFI presentaron contenidos estimados totales de AGB y C de 88,7 Gg AGB y 44,4 Gg C, respectivamente. Se estimó en $163 \mathrm{Gg} \mathrm{CO}_{2} \mathrm{e}$ las emisiones evitadas por deforestación.

\section{Discusión}

Este estudio arrojó las primeras estimaciones de AGB y $C$ en los bosques naturales de SFFI, en donde se observa la importancia de mediciones con el uso de PTM y la aplicación de ecuaciones alométricas para especies forestales andinas son de gran importancia para conocer las condiciones ecológicas de los bosques y su capacidad para el almacenamiento de C para la mitigación del cambio climático (Brown et al., 1993; Vashum \& Jayakumar, 2012; Reichstein \& Carvalhais, 2019). El trabajo de campo fue planificado para establecer y registrar la mayor cantidad de PTM (23 en total), en un inventario exploratorio y como un primer insumo para conocer las condiciones y el estado actual de los bosques del SFFI. Sin embargo, se hace necesario establecer nuevas PTM que mejoren la representatividad de la muestra, ya que son parámetros necesarios para la minimización de incertidumbres al realizar estimaciones de AGB y C con datos de campo y sensores remotos (Galindo et al., 2011).

Los valores estimados de AGB en este estudio fueron similares a los reportados por Clerici et al. (2016), con parcelas de $400 \mathrm{~m}^{2}$ en bosques andinos de Cundinamarca $(180,7 \pm 23,8 \mathrm{Mg} / \mathrm{ha})$ y los reportados por Yepes-Quintero et al. (2011), en parcelas de 1 ha en bosques de tierras altas de Antioquia con contenidos de AGB y C de 102,38 $\pm 25,22 \mathrm{Mg} / \mathrm{ha}$ y $51,19 \pm 12,61 \mathrm{Mg} \mathrm{C} / \mathrm{ha}$ respetivamente. La $A G B$ y $C$ estimado para el bosque andino del SFFI mostró una heterogeneidad en el dap de los árboles registrados en campo, esto indicó que se presentó en algún momento un proceso de intervención antrópica, lo cual concordó con lo señalado por Villareal et al. (2017), quien afirma que los bosques del SFFI se encuentran en estado de recuperación mientras que algunos otros fragmentos conservan su estructura original. Por otro lado, cabe resaltar que las condiciones ambientales de zonas montañosas, tal como alta nubosidad, vientos, pendientes, clima y suelo, a las que están sometidos estos bosques podrían evidenciar limitaciones en el crecimiento y desarrollo de las especies forestales y verse reflejado en la variabilidad en contenidos de AGB (Yepes et al., 2015).

Las correcciones en imágenes Landsat 8 utilizadas en este estudio presentaron ajustes radiométricos lo que mejoró la visualización de características espectrales de la superficie terrestre en especial la de bosques Andinos. La imágenes Landsat son muy utilizadas para estimación de AGB y C, ya que son de fácil acceso para la comunidad y presentan un largo catálogo lo que permite un monitoreo constante de la vegetación (Zhu \& Liu, 2015). Investigaciones realizadas por Banskota et al. (2014), Zhu \& Liu (2015), Clerici et 
al. (2016), Gizachew et al. (2016), Imran \& Ahmed, (2018) y Li et al. (2020) señalan la importancia de realizar correcciones previas a las imágenes de satélite para minimizar incertidumbres frente al comportamiento radiométrico en coberturas boscosas para la estimación de AGB y C con sensores remotos ópticos.

EI NDVI para la época seca presentó la mejor correlación frente a los datos de AGB de las PTM $(r=0,88)$ de igual manera, los índices de época lluviosa obtuvieron buenos rendimientos frente a la correlación con la AGB real $(0,6$ $<r<0,7)$. El uso de IV basados en las bandas rojas e infrarrojas obtienen buenos resultados en la estimación de AGB en bosques tropicales ya que están relacionados directamente con la actividad fotosintética (Macedo et al., 2018).

Las nueve PTM seleccionadas para la correlación y ajuste del modelo presentaron una densidad $\geq 30$ árboles/parcela, esto partiendo de la idea que un número mayor de árboles por píxel (densidad de la copa) debe estar asociado a mayores contenidos de AGB (Anaya et al., 2009; Wassihun et al., 2019). Se definió un rango de valores de NDVI mínimo y máximo de 0,61 y 0,68, respectivamente, valores que se encuentran dentro del rango reportado por Cargua et al. (2018), en bosques Andinos del Ecuador.

Sin embargo, se hace necesario profundizar en el estudio de los IV ya que al estar relacionados directamente con la capacidad fotosintética, estos pueden variar según las condiciones ambientales, climáticas y fenológicas propias de los ecosistemas forestales (Van Leeuwen et al., 2013; Millano \& Paredes, 2016; Suepa et al., 2016). Estos fenómenos pueden ser un factor relevante al momento de estimar AGB y C con sensores remotos en diferentes épocas del año (Zhu \& Liu, 2015; Macedo et al., 2018).

Este estudio desarrolló un modelo tipo exponencial $\left(R^{2}=0,82\right)$ el cual fue el de mejor ajuste según los criterios recomendados por Segura \& Kanninen (2005); Segura \& Andrade (2008) y Andrade et al. (2014), los resultados de los estadígrafos de ajuste fueron similares a los reportados por (Devagiri, 2013). De igual manera, los contenidos de AGB estimados vs los observados alcanzaron un RSME de 17, $1 \mathrm{Mg} / \mathrm{ha}$, esta métrica se utiliza para determinar el rendimiento del modelo y es fundamental para la evaluación del mismo (Li et al., 2020).

El modelo exponencial se basó en un número relativamente pequeño de PTM (nueve de 10 × 25 m) lo que reflejó una limitación en cuanto a su número; sin embargo, se convierte en un primer ejercicio de estimación de AGB y C en bosques Andinos del SFFI con sensores remotos. Si bien, existen estudios a nivel nacional con el mismo objetivo (Anaya et al., 2009; Galindo et al., 2011; Clerici et al., 2016), estos varían en el enfoque metodológico, escala de trabajo y la variabilidad en el tamaño y numero de parcelas utilizadas.

Geográficamente, la AGB y el C se encontró distribuida heterogéneamente, siendo la clase 1 la de mayor porcentaje $(8,3)$; pequeños parches de bosque conservados presentaron lo mayores diámetros localizados mayormente en la parte norte del SFFI lo que concuerda con lo señalado por Parques Nacionales Naturales (2006) y Villareal et al. (2017). Asimismo, se estimó el total de AGB y C 
para los bosques del SFFI en 88,7 Gg AGB y 44,4 Gg C, respectivamente, siendo las primeras aproximaciones a los contenidos de $A G B$ y $C$ en estos bosques. De igual manera, se estimó que cerca de $163 \mathrm{Gg} \mathrm{CO}_{2}$ e se podrían emitir en caso de deforestación; este resultado es importante para el planteamiento de políticas que busquen la protección de estos bosques en la búsqueda de mejorar la capacidad de adaptación y mitigación al cambio climático en la región (Phillips et al., 2011; Saatchi et al., 2011). Generar cartografía de la distribución de los contenidos de AGB y C se hace necesario para ampliar las posibilidades de monitoreo a escala local y regional (Gibbs et al., 2007; GOFC-GOLD, 2016; Rodríguez-Veiga et al., 2016).

\section{Conclusiones}

Este estudio aportó las primeras estimaciones de AGB y C real en los bosques del SFFI datos que estuvieron en promedio en 73,1 Mg/ha y 36,6 Mg C/ha respectivamente. El uso de imágenes Landsat 8, técnicas de Teledetección y el uso de IV reflejaron una alternativa para la estimación indirecta de AGB y $C_{\text {; }}$ en este estudio se determinó un modelo tipo exponencial para un NDVI de temporada seca con un $\mathrm{R}^{2}=0,82$ lo cual reflejó un buen ajuste; asimismo, se determinó que los mayores rangos de AGB y $C$ se encuentran en alturas que correspondieron entre los 3000 y 3300 m y se encuentran localizados heterogéneamente en la zona sureste y norte del SFFI siendo estos sitios los de mayor interés para la conservación y monitoreo; se estimó en 136 Gg CO $2 \mathrm{e}$ las emisiones evitadas a la atmosfera por deforestación siendo el potencial de estos bosques como Stoks de C. Los resultados aquí expuestos brindan una oportunidad para llevar a cabo el monitoreo de AGB y C en bosques Andinos y una alternativa de monitoreo en áreas de importancia ambiental.

\section{Agradecimientos}

Este estudio se desarrolló bajo el contexto del proyecto denominado "Caracterización florística y almacenamiento de carbono en bosques nativos en el Santuario de Fauna y Flora de Iguaque, Boyacá, Colombia" del Grupo de Investigación Producción Ecoamigable de Cultivos Tropicales "PROECUT" de la Universidad del Tolima. Asimismo, los autores agradecen a Parques Nacionales Naturales de Colombia PNNC y en especial al equipo administrativo y funcionarios técnicos del Santuario de Fauna y Flora de Iguaque con sede en Villa de Leyva, Boyacá, por todo el apoyo en el trabajo de campo.

\section{Bibliografía}

Aguilar-Arias, H., Mora-Zamora, R., \& Vargas-Bolaños, C. (2014). Metodología para la corrección atmosférica de imágenes aster, rapideye, spot 2 y landsat 8 con el 
módulo FLAASH del software ENVI. Revista Geográfica de América Central, 2(53), 39-59. http://doi.org/10.15359/rgac.2-53.2

Anaya, A., Chuvieco, E., \& Palacios-Orueta, A. (2009). Forest ecology and management aboveground biomass assessment in Colombia: A remote sensing approach. Forest Ecology and Management, 257, 1237-1246. http://doi.org/10.1016/j.foreco.2008.11.016

Andrade-Castañeda, H. J., Arteaga-Céspedes, C. C., \& Segura-Madrigal, M. A. (2017). Emisión de gases de efecto invernadero por uso de combustibles fósiles en Ibagué, Tolima (Colombia). Corpoica Ciencia y Tecnología Agropecuaria, 18(1), 103-112.

Andrade, H. J., Segura, M., \& Forero, A. (Eds.) (2014). Desarrollo de modelos alométricos para volumen de madera, biomasa y carbono en especies leñosas perennes: conceptos básicos, métodos y procedimientos, ISBN: 978-958-8747-58-3. Ibagué, Colombia. Universidad del Tolima.

Ariza, A. (2013). Descripción y Corrección de Productos Landsat 8 LDCM (Landsat Data Continuity Mission) Versión 1.0. Centro de Investigación y Desarrollo (CIAF), Instituto Geográfico Agustín Codazzi. Recuperado de: www.un-spider.org/sites/default/files/LDCM-L8.R1.pdf

Banskota, A., Kayastha, N., Falkowski, M. J., Wulder, M. A., Froese, R. E., White, J. C., ... Canada, N. R. (2014). Forest monitoring using landsat time series data: a review. Canadian Journal of Remote Sensing, 40(5), 362-384. http://doi.org/10.1080/07038992.2014.987376

Brown, S. (1997). Estimating Biomass and Biomass Change of Tropical Forests: A Primer. FAO Forest Paper 134. ISBN: 92-5-103955-0. Roma, Italia. Food and Agriculture Organization of the United Nations (FAO).

Brown, S., Hall, C. A. S., Knabe, W., Raich, J., Trexler, M. C., \& Woomer, P. (1993). Tropical forests: their past, present, and potential future role in the terrestrial carbon budget. Water Air Soil Pollut, 70, 71-94. http://doi.org/10.1007/BF01104989

Cargua, F., Rodriguez, M., Romero, B., \& Santillan, P. (2018). Evaluación del estado de conservación del bosque de ceja Andina sur occidental del Parque Nacional Sangay (Ecuador), para una mejor gestión del recurso forestal. Revista Espacios, 39(45), 29.

Chuvieco, E. (Eds.) (2010). Teledetección Ambiental (3a. edición). ISBN: 978-84-344-8073-3, Barcelona, España, Ariel Editorial.

Clerici, N., Rubiano, K., Abd-Elrahman, A., Posada, J., \& Escobedo, F. J. (2016). Estimating aboveground biomass and carbon stocks in periurban andean secondary forests using very high resolution imagery. Forests. 7, 1-17.

http://doi.org/10.3390/f7070138

Corral-Rivas, J. J., Vargas-Larreta, B., Wehenkel, C., Aguirre-Calderón, O., \& CrecenteCampo, F. (2013). Guía para el establecimiento, seguimiento y evaluación de sitios permanentes de monitoreo en paisajes productivos forestales. Comision Nacional Forestal (CONAFOR). Recuperado de: http://forestales. ujed.mx/monafor/archivos/descargas/guias_manuales/Guia_pa-ra_el_ Establecimiento_Seguimiento_y_Evaluación_de_Sitios_Permanetes_de_ Monitoreo.pdf 
Devagiri, G. M., Money, S., Singh, S., Dadhawal, V. K., \& Patil, P. (2013). Assessment of above ground biomass and carbon pool in different vegetation types of south western part of Karnataka, India using spectral modeling. Tropical Ecology, 54(2), 149-165.

Di Rienzo, J. A., Casanoves, F., Balzarini, M. G., González, L., Tablada, M., \& Robledo, C. W. (2016). InfoStat. InfoStat Software Estadístico. Grupo InfoStat, FCA, Universidad Nacional de Córdoba, Argentina. Recuperado de: https://www.infostat.com.ar/

Eastman, J. R. (2006). IDRISI Andes Guide to GIS and Image Processing. Manual Version 15.00. Worcester, USA. Clark Labs, Clark University. Recuperado de: http:// www.cartografia.cl/download/manuales/idrisi_andes.pdf

Environmental Systems Research Institute (ESRI) (2014). ArcGIS Desktop 10.3. Redlands, USA.

Fernández-Méndez, F., Velasco-Salcedo, V. E., Guerrero-Contecha, J., Galvis, M., \& Neri, A. V. (2016). Recuperación ecológica de áreas afectadas por un incendio forestal en la microcuenca Tintales (Boyacá, Colombia). Colombia Forestal, 19(2), 143160.

Galindo, G., Cabrera, E., Vargas, D., Pabón, H., Cabrera, K., Yepes, A., ... Ordoñez, M. (Eds.) (2011). Estimación de la Biomasa Aérea Usando Datos de Campo e Información de Sensores Remotos Version 1.0. ISBN: 978-958-8067-50-6 Bogotá D.C, Colombia. Instituto de Hidrología, Meteorología, y Estudios Ambientales-IDEAM. Editorial Scripto Ltda.

Gibbs, H. K., Brown, S., Niles, J. O., \& Foley, J. A. (2007). Monitoring and estimating tropical forest carbon stocks: making REDD a reality. Environmental Research Letters, 2, 1-13. http://doi.org/10.1088/1748-9326/2/4/045023

Gilabert, M. A., González-Piqueras, J., \& Garcia-Haro, J. (1997). Acerca de los índices de vegetación. Revista de Teledetección, (8), 1-10.

Gizachew, B., Solberg, S., Næsset, E., Gobakken, T., Bollandsås, O. M., Breidenbach, J., ... Mauya, E. W. (2016). Mapping and estimating the total living biomass and carbon in low - biomass woodlands using Landsat 8 CDR data. Carbon Balance and Management, 11(13), 1-14. http://doi.org/10.1186/s13021-016-0055-8

Global Observation of Forest and Land Cover Dynamics (GOFC-GOLD) (2016). A sourcebook of methods and procedures for monitoring and reporting anthropogenic greenhouse gas emissions and removals associated with deforestation, gains and losses of carbon stocks in forests remaining forests, and forestation. Holanda: Report version-COP22-1, GOFC-GOLD Land Cover Project Office, Wageningen University. Recuperado de: http://www.gofcgold.wur.nl/redd/sourcebook/ GOFC-GOLD_Sourcebook.pdf

Günlü, A., Ercanli, I., Başkent, E., \& Çakır, G. (2014). Estimating aboveground biomass using Landsat TM imagery: A case study of Anatolian Crimean pine forests in Turkey. Annals of Forest Research, 57, 289-298.

Hantson, S., \& Chuvieco, E. (2011). Evaluation of different topographic correction methods for Landsat imagery. International Journal of Applied Earth Observation and Geoinformation, 13(5), 691-700.

https://doi.org/https://doi.org/10.1016/j.jag.2011.05.001 
Huete, A., Justice, C., \& Leeuwen, W. Van (1999). MODIS Vegetation Index (MOD 13) Algorithm Theoretical Basis Document Version 3. NASA. Goddard Space Flight Center.

Huete, A. R. (1988). Soil Adjusted Vegetation Index (SAVI). Remote Sensing of Environment, 25, 295-309. http://doi.org/10.1016/0034-4257(88)90106-X

Imran, A. B., \& Ahmed, S. (2018). Potential of Landsat-8 spectral indices to estimate forest biomass. International Journal of Human Capital in Urban Management, 3(4), 303-314. http://doi.org/10.22034/JJHCUM.2018.04.04

Intergovernmental Panel on Climate Change (IPCC) (2007). Climate Change 2007 - The Physical Science Basis. Contribution of Working Group I to the Fourth Assessment Report of the IPCC. New York, USA: Cambridge University Press. Recuperado de: https://www.ipcc.ch/site/assets/uploads/2018/05/ar4_wg1_full_report-1.pdf

Lerma, M., \& Orjuela, E. (2014). Modelos Alométricos para la Estimación de la Biomasa Aérea Total en el Páramo de Anaime, Departamento del Tolima, Colombia. Tesis de Pregrado. Universidad del Tolima. Ibagué, Colombia. Re-cuperado de: https://bit.ly/3k8iLPP

Li, C., Li, Y., \& Li, M. (2019). Improving forest aboveground biomass (AGB) estimation by incorporating crown density and using Landsat $8 \mathrm{OLI}$ images of a subtropical forest in western Hunan in Central China. Forests, 10, 1-17. http://doi.org/10.3390/f10020104

Li, Y., Li, M., Li, C., \& Liu, Z. (2020). Forest aboveground biomass estimation using Landsat 8 and Sentinel-1A data with machine learning algorithms. Scientific Reports, 10, 9952. http://doi.org/10.1038/s41598-020-67024-3

Lu, D. (2006). The potential and challenge of remote sensing-based biomass estimation. International Journal of Remote Sensing, 27(7), 1297-1328. http://doi.org/10.1080/01431160500486732

Lu, D., Chen, Q., Wang, G., Moran, E., Batistella, M., Zhang, M., ... Saah, D. (2012). Aboveground forest biomass estimation with Landsat and LiDAR Data and uncertainty analysis of the estimates. International Journal of Forestry Research, (1), 1-16. http://doi.org/10.1155/2012/436537

Macedo, F. L., Sousa, A. M. O., Gonçalves, A. C., da Silva, J. R., Mesquita, P. A., \& Rodrigues, R. A. F. (2018). Above-ground biomass estimation for Quercus rotundifolia using vegetation indices derived from high spatial resolution satellite images. European Journal of Remote Sensing, 51(1), 932-944. http://doi.org/10.1080/22797254.2018.1521250

Main-knorn, M., Cohen, W. B., Kennedy, R. E., Grodzki, W., Dirk, P., Grif, P., \& Hostert, P. (2013). Remote sensing of environment monitoring coniferous forest biomass change using a Landsat trajectory-based approach. Remote Sensing of Environment, 139, 277-290. http://doi.org/10.1016/j.rse.2013.08.010

Martínez-Barrón, R. A., Aguirre-Calderón, O. A., Vargas-Larreta, B., Jiménez-Pérez, J., Treviño-Garza, E. J., \& Yerena-Yamallel, J. I. (2016). Modelación de bio-masa y carbono arbóreo aéreo en bosques del estado de Durango. Revista Mexicana de Ciencias Forestales, 7(35), 91-106.

https://doi.org/https://doi.org/10.29298/rmcf.v7i35.77 
Millano, J. L., \& Paredes, F. J. (2016). Variabilidad de la vegetación con el Índice de Diferencia Normalizada (NDVI) en Latinoamérica. Novum Scientiarum, 2(4), 33-44.

NASA-METI (2011). ASTER Global Digital Elevation Model V002. NASA EOSDIS Land Processes [ID ASTGTM2_N05W074].

Nguyen, H. C., Jung, J., Lee, J., Choi, S.-U., Hong, S.-Y., \& Heo, J. (2015). Optimal Atmospheric correction for above-ground forest biomass estimation with the ETM+ remote sensor. Sensors, 15, 18865-18886. http://doi.org/10.3390/s150818865

Padrón, E., \& Navarro-Cerrillo, R. (2007). Aboveground biomass in Prosopis pallida (Humb. and Bonpl. ex Willd.) H. B. K. ecosystems using Landsat 7 ETM+ images. Revista Chilena de Historia Natural, 80, 43-53.

Parques Nacionales Naturales (PNN) (2006). Plan de Manejo Santuario de Fauna y Flora Iguaque. Parques Nacionales Naturales de Colombia. Recuperado de: humboldt.org.co/es/...de.../279-plan-de-manejo-santuario-de-fauna-y-floraiguaque

Parques Nacionales Naturales (PNN) (2018). Atlas de Carbono de las Áreas del Sistema de Parques Nacionales Naturales de Colombia. Subdirección de Sostenibilidad y Negocios Ambientales, Parques Nacionales Naturales de Colombia. Recuperado de: http://www.parquesnacionales.gov.co/portal/wp-content/ uploads/2018/07/Atlas-de-Carbono-DTAN-1.pdf

Pechanec, V., Stržínek, F., Purkyt, J., Štěrbová, L., \& Cudlín, P. (2017). Carbon stock in forest aboveground biomass - comparison based on Landsat data. Central European Foresty Journal, 63, 126-132. http://doi.org/10.1515/forj-2017-0014

Phillips, J. F., Duque, A. J., Cabrera, K. R., Yepes, A. P., Navarrete, D. A., García, M. C., ... Vargas, D. M. (Eds.) (2011). Estimación de las reservas potenciales de carbono almacenadas en la biomasa aérea en bosques naturales de Colombia. ISBN: 978958-8067-33-9. Bogotá D.C, Colombia. Instituto de Hidrología, Meteorología, y Estudios Ambientales. Editorial Scripto.

Pimple, U., Sitthi, A., Simonetti, D., Pungkul, S., Leadprathom, K., \& Chidthaisong, A. (2017). Topographic correction of Landsat TM-5 and Landsat OLI-8 Imagery to improve the performance of forest classification in the mountainous terrain of northeast Thailand. Sustainability, 9, 1-26. http://doi.org/10.3390/su9020258

Powell, S. L., Cohen, W. B., Healey, S. P., Kennedy, R. E., Moisen, G. G., Pierce, K. B., \& Ohmann, J. L. (2010). Remote Sensing of environment quantifi cation of live aboveground forest biomass dynamics with Landsat time-series and field inventory data: A comparison of empirical modeling approaches. Remote Sensing of Environment, 114, 1053-1068. http://doi.org/10.1016/j.rse.2009.12.018

Qiu, A., Yang, Y., Wang, D., Xu, S., \& Wang, X. (2019). Exploring parameter selection for carbon monitoring based on Landsat-8 imagery of the aboveground forest biomass on Mount Tai. European Journal of Remote Sensing, 53, 1-12. http://doi.org/10.1080/22797254.2019.1686717

Reichstein, M., \& Carvalhais, N. (2019). Aspects of forest biomass in the Earth system: Its role and major unknowns. Surveys in Geophysics, 40(4), 693-707. http://doi.org/10.1007/s10712-019-09551-x

Rhyma, P. P., Norizah, K., Hamdan, O., Faridah-Hanum, I., \& Zulfa, A. W. (2020). Integration of normalised different vegetation index and Soil-Adjusted Vegetation Index 
for mangrove vegetation delineation. Remote Sensing Applications: Society and Environment, 17, 1-7. http://doi.org/10.1016/j.rsase.2019.100280

Rodríguez-Veiga, P., Saatchi, S., Tansey, K., \& Balzter, H. (2016). Magnitude, spatial distribution and uncertainty of forest biomass stocks in Mexico. Remote Sensing of Environment, 183, 265-281. http://doi.org/10.1016/j.rse.2016.06.004

Rodríguez-Veiga, P., Wheeler, J., Louis, V., Tansey, K., \& Balzter, H. (2017). Quantifying Forest biomass carbon stocks from space. Current Forestry Reports, 3(1), 1-18. http://doi.org/10.1007/s40725-017-0052-5

Rouse, J. W., Haas, R. H., Shell, J. A., \& Deering, D. (1974). Monitoring vegetation systems in the Great Plains with ERTS. Proceedings of the Third Earth Resources Technology Satellite- 1 Symposium Volume I: Technical presentations. NASA. Goddard Space Flight Center. 301-317. Recuperado de: https://ntrs.nasa.gov/ citations/19740022614

Roy, P. S., \& Ravan, S. A. (1996). Biomass estimation using satellite remote sensing data - An investigation on possible approaches for natural forest. Journal of Biosciences, 21(4), 535-561.

Saatchi, S., Houghton, R. A., Alvalá Dos Santos, R. C., Soares, J. V., \& Yu, Y. (2007). Distribution of aboveground live biomass in the Amazon basin. Global Change Biology, 13, 816-837. http://doi.org/10.1111/j.1365-2486.2007.01323.x

Saatchi, S. S., Harris, N. L., Brown, S., Lefsky, M., Mitchard, E. T. A., Salas, W., ... Morel, A. (2011). Benchmark map of forest carbon stocks in tropical regions across three continents. Proceedings of the National Academy of Sciences, 108(24), 98999904. http://doi.org/10.1073/pnas.1019576108

Segura, M., \& Andrade, H. J. (2008). ¿Cómo construir modelos alométricos de volumen, biomasa o carbono de especies leñosas perennes? Agroforestería en Las Américas, 46, 89-96.

Segura, M., \& Kanninen, M. (2005). Allometric models for tree volume and total aboveground biomass in a tropical humid forest in Costa Rica. Biotropica, 37(1). http://doi.org/10.1111/j.1744-7429.2005.02027.x

Silleos, N. G., Alexandridis, T. K., Gitas, I. Z., \& Perakis, K. (2006). Vegetation indices: Advances made in biomass estimation and vegetation monitoring in the last 30 years. Geocarto International, 21(4), 21-28.

Suepa, T., Qi, J., Lawawirojwong, S., \& Messina, J. P. (2016). Understanding spatio-temporal variation of vegetation phenology and rainfall seasonality in the monsoon Southeast Asia. Environmental Research, 147, 621-629. http://doi.org/10.1016/j. envres.2016.02.005

Teillet, P., Guindon, B., \& Goodenough, D. (1982). On the slope-aspect correction of multispectral scanner data. Canadian Journal of Remote Sensing, 8(2), 84-106. http://doi.org/10.1080/07038992.1982.10855028

Timothy, D., Onisimo, M., Cletah, S., \& Adelabu, S. (2016). Remote sensing of aboveground forest biomass: A review. Tropical Ecology, 57(2), 125-132.

United States Geological Survey (USGS) (2016a). USGS EROS Archive - Landsat Archives Landsat 8 OLI (Operational Land Imager) and TIRS (Thermal In-frared Sensor) Level-1 Data Products. U.S Geological Survey. Landsat 8 OLI/TIRS Collection 1. Landsat Scene ID LC80070562016032LGN00.

United States Geological Survey (USGS) (2016b). USGS EROS Archive-Landsat ArchivesLandsat 8 OLI (Operational Land Imager) and TIRS (Thermal In-frared Sensor) 
Level-1 Data Products. Landsat 8 OLI/TIRS Collection 1. Landsat Scene ID LC80070562016144LGN00.

United States Geological Survey (USGS) (2018). Landsat 8 (L8) data users handbookVersion 3.0. Sioux Falls, USA. Recuperado de: https://prd-wret.s3-us-west-2. amazonaws.com/assets/palladium/production/s3fs-public/atoms/files/LSDS1574_L8_Data_Users_Handbook.pdf

Van Leeuwen, W. J. D., Hartfield, K., Miranda, M., \& Meza, F. J. (2013). Trends and ENSO/ AAO driven variability in NDVI derived productivity and phenology alongside the Andes mountains. Remote Sensing, 5(3) 1177-1203. http://doi.org/10.3390/rs5031177

Vashum, K. T., \& Jayakumar, S. (2012). Methods to Estimate Above-Ground Biomass and Carbon Stock in Natural Forests - A Review. Journal of Ecosystem \& Ecography, 2(4), 1-7. http://doi.org/10.4172/2157-7625.1000116

Villareal, H., Nuñez, M., Zorro, W., \& Pacheco, C. (2017). Plan de manejo del Santuario de Fauna y Flora Iguaque. Parques Nacionales Naturales de Colombia. Recuperado de: http://www.parquesnacionales.gov.co/portal/wp-content/ uploads/2018/06/PM-SFF-IGUAQUE-adoptado.pdf

Wassihun, A. N., Hussin, Y. A., Leeuwen, L. M. Van, \& Latif, Z. A. (2019). Effect of forest stand density on the estimation of above ground biomass/carbon stock using airborne and terrestrial LIDAR derived tree parameters in tropical rain forest, Malaysia. Environmental Systems Research, 8(27), 1-15. http://doi.org/10.1186/s40068-019-0155-z

Wu, X., Furby, S., \& Wallance, J. (2004). An approach for terrain illumination correction. Proc of 12th Australasian Remote Sensing and Photogrammetry Conference. Recuperado de: https://publications.csiro.au/rpr/pub?list=BRO\&pid=procite:2 7c185ad-8c81-43f6-b383-ec0948959e62

Yepes-Quintero, A., Duque-Montoya, Á., Navarrete-Encinales, D., Phillips-Bernal, J., Cabrera-Montenegro, E., Corrales-Osorio, A., ... Vargas-Galvis, D. (2011). Estimación de las reservas y pérdidas de carbono por deforestación en los bosques del departamento de Antioquia, Colombia. Actualidades Biológicas, 33(95), 193-208.

Yepes, A., Herrera, J., Phillips, J., Cabrera, E., \& Galindo, G. (2015). Contribución de los bosques tropicales de montaña en el almacenamiento de carbono en Colombia. Revista de Biología Tropical, 63(1), 69-82.

http://doi.org/10.15517/rbt.v63i1.14679

Zhu, X., \& Liu, D. (2015). Improving forest aboveground biomass estimation using seasonal Landsat NDVI time-series. ISPRS Journal of Photogrammetry and Remote Sensing, $102,222-231$. http://doi.org/http://dx.doi.org/10.1016/j.isprsjprs.2014.08.014

Zhu, Z., Wulder, M. A., Roy, D. P., Woodcock, C. E., Hansen, M. C., Radelo, V. C., ... Scambos, T. A. (2019). Benefits of the free and open Landsat data policy. Remote Sensing of Environment, 224, 382-385. http://doi.org/10.1016/j.rse.2019.02.016 